\title{
A Conformationally Constrained Nucleotide Analog Controls the Folding Topology of a DNA G-Quadruplex
}

\author{
Pamela K. Dominick and Michael B. Jarstfer*
}

Division of Medicinal Chemistry and Natural Products, School of Pharmacy, University of North Carolina, Chapel Hill, North Carolina 27599-7360

\section{Experimental Procedures}

Oligonucleotides used. $\underline{\mathbf{N}}$ denotes an LNA residue.

$\begin{array}{lllllllll} & 1 & 4 & 8 & 12 & 16 & 20 & 24 & 28\end{array}$

Oxy28_4: 5'-GGGGTTTTGGGGTTTTGGGGTTTTGGGG

Oxy28_5: 5'-GGGG

Oxy28_6: 5'-GGGGTITTTGGGGTTTTGGGGTTTTGGGG

Oxy28_15: 5'-GGGGTTTTGGGGTTITTGGGGTTTTGGGG

Oxy28_16: 5'-GGGGTTTTGGGGTTTTEGGGGTTTTGGGG

Oxy28_17: 5'-GGGGTTTTGGGGTTTTEGGGGTTTTGGGG

Oxy28_18: 5'-GGGGTTTTGGGGTTTTG_GGGTTTTGGGG

Oxy 28 was purchased from IDT (Coralville, IA) and LNA-containing oligonucleotides were a gift from Proligo (Boulder, $\mathrm{CO}$ ). Oligonucleotides were purified by gel electrophoresis and desalted using a G25 desalting column (Amersham). Purity was established by resolving the oligonucleotides using denaturing gel electrophoresis and visualizing with SYBR green (Molecular Probes).

Nondenaturing gel electrophoresis. Oligonucleotides (25 pmol) were labeled with $25 \mathrm{pmol}\left[\gamma_{-}{ }^{32} \mathrm{P}\right]-\mathrm{ATP}(10 \mathrm{Ci} / \mathrm{mmol}) \mathrm{using}$ polynucleotide kinase. G-quadruplexes were formed by heating a $20 \mu \mathrm{L}$ solution of $1 \mu \mathrm{M}$ oligonucleotides (diluted to 2000 $\mathrm{cpm} / \mathrm{pmol})$ in $10 \mathrm{mM}$ potassium phosphate $(\mathrm{pH}=7.5)$ and $40 \mathrm{mM} \mathrm{KCl}$ for $5 \mathrm{~min}$ at $95{ }^{\circ} \mathrm{C}$ then slow cooling $\left(1^{\circ} \mathrm{C} \mathrm{min}{ }^{-1}\right)$ the

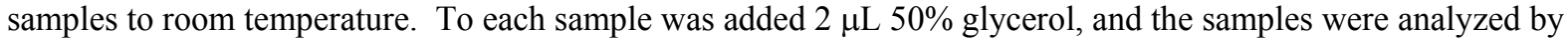
nondenaturing gel electrophoresis on a $20 \mathrm{~cm} \times 20 \mathrm{~cm}, 15 \%$ polyacrylamide (19:1 acrylamide:bisacrylamide ratio) gel containing $0.5 \times \mathrm{TBE}$ and $50 \mathrm{mM} \mathrm{KOAc}$. Gels were run for 4 hours at $10 \mathrm{~V} / \mathrm{cm}$ at ambient temperature. Lowering the running temperature did not influence the results. Gels were dried and exposed to phosphorimager plates over night then visualized using a Molecular Dynamics Phosphorimager (Storm 860) and converted to an image file using ImageQuant.

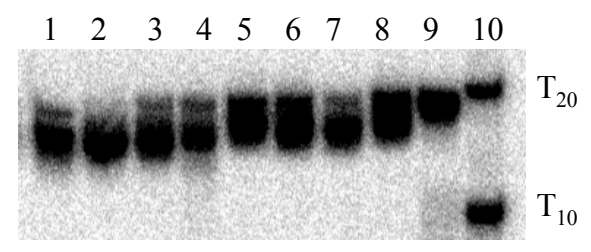

Figure S1. Nondenaturing polyacrylamide gel electrophoresis of folded G-quadruplex-forming oligonucleotides. Lane 1: Oxy28, lane 2: $O x y 28 \_2$, lane 3: $O x y 28 \_4$, lane 4: Oxy28_5, lane 5: Oxy28_6, lane 6: Oxy28_15, lane 7: Oxy28_16, lane 8: Oxy28_17, lane 9: Oxy $28 \_18$, lane 10: $\mathrm{T}_{10}$ and $\mathrm{T}_{20}$ oligonucleotide markers. 
CD Spectroscopy. Oligonucleotides were annealed by heating samples for 5 min at $95{ }^{\circ} \mathrm{C}$ then slow cooling $\left(1{ }^{\circ} \mathrm{C} \min ^{-1}\right)$ to room temperature in a buffer of $10 \mathrm{mM} \mathrm{K}^{+}$or $\mathrm{Na}^{+}$phosphate $(\mathrm{pH}=7.5)$ containing either $40 \mathrm{mM} \mathrm{KCl}$ or NaCl, respectively. Experiments were performed at both 5 and $25 \mu \mathrm{M}$ oligonucleotide. CD spectra were recorded on an Applied Photophysics Pistar-180 Circular Dichroism spectrophotometer equipped with a Peltier temperature controller. For each sample, spectral scans were accumulated over the wavelength range $200-350 \mathrm{~nm}$ at $25^{\circ} \mathrm{C}$ and at $95{ }^{\circ} \mathrm{C}$ in a $1 \mathrm{~mm}$ path length cell at a scanning rate of $20 \mathrm{~nm} / \mathrm{min}$. 2 scans were averaged for each sample. The scan of the buffer alone was subtracted from each sample. CD spectra were collected in units of millidegrees versus wavelength and normalized to the strand concentration and number of residues. The spectra for each oligonucleotide folded in $\mathrm{Na}^{+}$were indistinguishable, thus only the spectra for the oligonucleotides folded in the presence of $\mathrm{K}^{+}$are shown (Figure S2).

UV Melting Curves. UV melting curves were monitored at $295 \mathrm{~nm}$ in a buffer of $10 \mathrm{mM} \mathrm{K}^{+}$or $\mathrm{Na}^{+}$phosphate $(\mathrm{pH}=7.5)$ containing either $40 \mathrm{mM} \mathrm{KCl}$ or NaCl, respectively, and a reference containing only buffer was also monitored. The temperature was ramped from $10{ }^{\circ} \mathrm{C}$ to $95^{\circ} \mathrm{C}$ at a rate of $1{ }^{\circ} \mathrm{C} \mathrm{min}^{-1}$. Samples, either 5 or $25 \mu \mathrm{M}$, were annealed as described above prior to analysis. Melting temperatures were calculated from the first derivative of the absorbance versus temperature curves (data not shown).

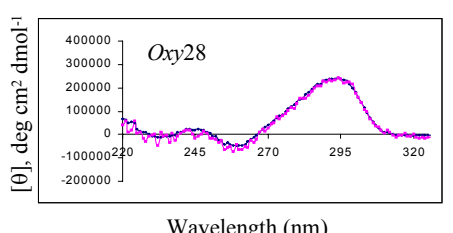

Wavelength $(\mathrm{nm})$
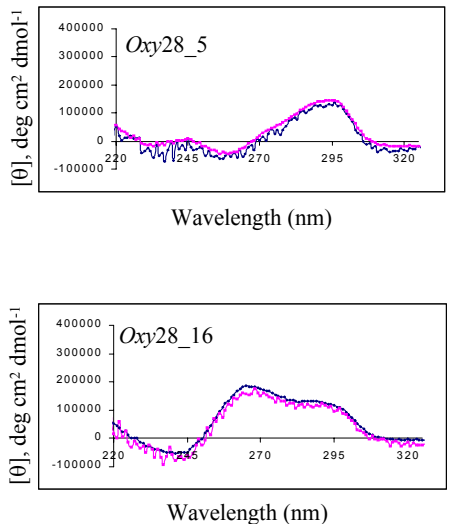

$25 \mu \mathrm{M}$

$5 \mu \mathrm{M}$

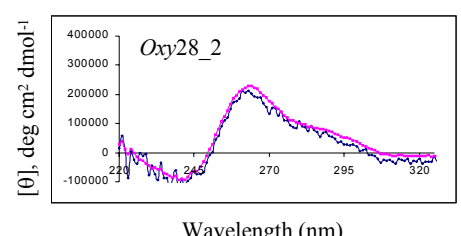

Wavelength (nm)

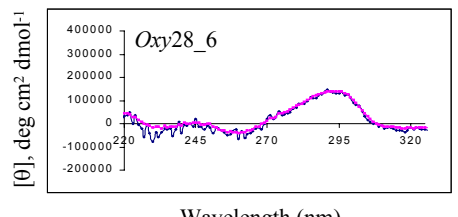

Wavelength (nm)

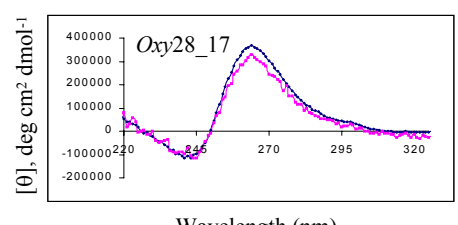

Wavelength (nm)

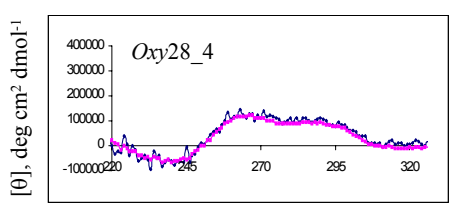

Wavelength (nm)

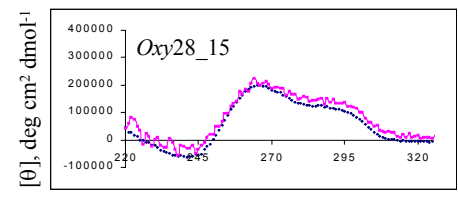

Wavelength (nm)

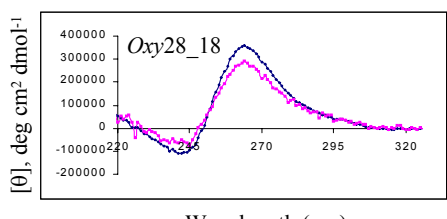

Wavelength (nm)

Figure S2. CD spectra of G-quadruplex-forming oligonucleotides in the presence of $\mathrm{K}^{+}$. Oligonucleotides were annealed in $50 \mathrm{mM} \mathrm{K}^{+}$as described in the experimental detail. 